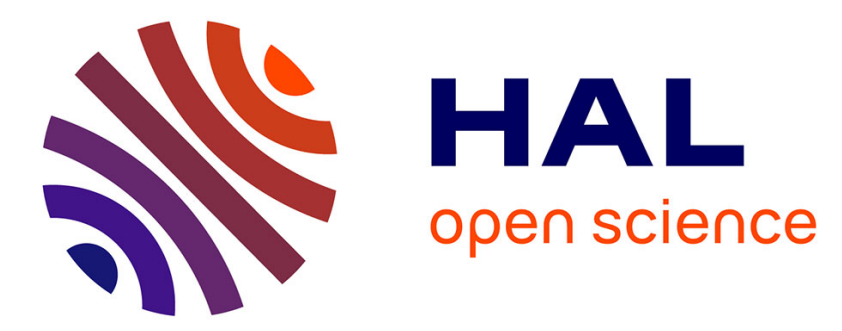

\title{
Male sperm whale acoustic behavior observed from multipaths at a single hydrophone
}

Christophe Laplanche, Olivier Adam, Maciej Lopatka, Jean-François Motsch

\section{To cite this version:}

Christophe Laplanche, Olivier Adam, Maciej Lopatka, Jean-François Motsch. Male sperm whale acoustic behavior observed from multipaths at a single hydrophone. Journal of the Acoustical Society of America, 2005, Vol. 118, pp. 2677-2687. 10.1121/1.2033567 . hal-00797687

\section{HAL Id: hal-00797687 \\ https://hal.science/hal-00797687}

Submitted on 7 Mar 2013

HAL is a multi-disciplinary open access archive for the deposit and dissemination of scientific research documents, whether they are published or not. The documents may come from teaching and research institutions in France or abroad, or from public or private research centers.
L'archive ouverte pluridisciplinaire HAL, est destinée au dépôt et à la diffusion de documents scientifiques de niveau recherche, publiés ou non, émanant des établissements d'enseignement et de recherche français ou étrangers, des laboratoires publics ou privés. 


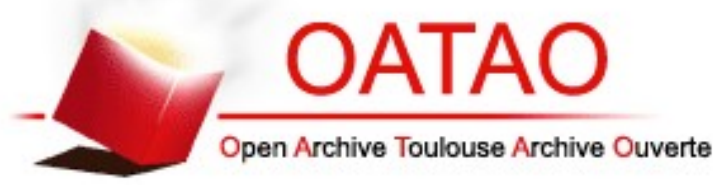

\section{Open Archive Toulouse Archive Ouverte (OATAO)}

OATAO is an open ac cess repository that collects the work of To ulouse re searchers and makes it freely available over the web where possible.

This is an author-deposited ver sion p ublished in: http://oatao.univ-toulouse.fr/ Eprints ID: 5605

To link to this article: DOI: $10.1121 / 1.2033567$

http://dx.doi.org/10.1121/1.2033567

To cite th is version: Laplanche, Christophe and Adam, Olivier and Lopatka, Maciej a nd M otsch, Jean-François Male sperm whale acoustic behavior observed from multipaths at a single hydrophone. (2005) The Journal of the Acoustical Society of Ameri ca (JASA), Vol. 118 (n ${ }^{\circ}$ ). pp. 2677-268 7. ISSN 0001-4966

Any correspondence concerning this service should be sent to the repository administrator: staff-oatao@inp-toulouse.fr 


\title{
Male sperm whale acoustic behavior observed from multipaths at a single hydrophone
}

\author{
Christophe Laplanche, ${ }^{\text {a) }}$ Olivier Adam, Maciej Lopatka, and Jean-François Motsch \\ Laboratoire Images, Signaux et Systèmes Intelligents Groupe Ingénierie des Signaux Neuro-Sensoriels, \\ Université Paris XII, France
}

\begin{abstract}
Sperm whales generate transient sounds (clicks) when foraging. These clicks have been described as echolocation sounds, a result of having measured the source level and the directionality of these signals and having extrapolated results from biosonar tests made on some small odontocetes. The authors propose a passive acoustic technique requiring only one hydrophone to investigate the acoustic behavior of free-ranging sperm whales. They estimate whale pitch angles from the multipath distribution of click energy. They emphasize the close bond between the sperm whale's physical and acoustic activity, leading to the hypothesis that sperm whales might, like some small odontocetes, control click level and rhythm. An echolocation model estimating the range of the sperm whale's targets from the interclick interval is computed and tested during different stages of the whale's dive. Such a hypothesis on the echolocation process would indicate that sperm whales echolocate their prey layer when initiating their dives and follow a methodic technique when foraging.
\end{abstract}

\section{INTRODUCTION}

The scientific community is compelled to research sperm whales (Physeter macrocephalus) for a variety of reasons; some researchers may strive to assess the risks associated with anthropogenic noise (Gisiner, 1998), while others conduct experiments to protect the whales from excessive boat traffic (Delory et al., 2002). Another motivation is the quest for new knowledge regarding the foraging behavior of sperm whales, since this aspect of their behavior is still the most puzzling (Fristrup and Harbison, 2002; Jaquet, 1996). Underwater visual observations of free-ranging, foraging sperm whales have never been carried through convincingly (Mccarey and Rubin, 1998), and the information available on the sperm whale diet is limited to stomach or fecal samplings. This is due to the fact that sperm whales mostly feed on mid sea and deep sea squid and fish, and at such depths research is difficult to conduct (Santos et al., 2001; Smith and Whitehead, 2000). However, many experiments have been conducted to address the whales' foraging behavior, using tagging techniques, visual observations, and passive acoustics.

Tagging sperm whales with depth-meters has led to an understanding of their diving behavior. Sperm whales undertake series of 30-90-min four-stage foraging cycles, composed of a breathing break at the sea surface, a vertical descent to the hunting depth, the hunt itself, and a vertical resurfacing (Watkins et al., 1993). Visual observations of sperm whales breathing at the sea surface provide some understanding of their social behavior. For instance, the males tend to travel solitarily, whereas the females and their calves travel in groups (Arnbom and Whitehead, 1989).

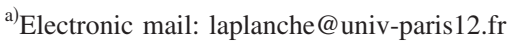

The use of passive acoustics enables scientists to better understand the sperm whale acoustic activity. Sperm whales emit a multitude of transient sounds (clicks) when diving. The function of the clicks may be to communicate (Watkins and Schevill, 1977; Weilgart, 1990) or echolocate (Jaquet et al., 2001; Mohl et al., 2000). The directionality and source level of the clicks are measured to determine their use in communication or echolocation (Madsen et al., 2002b). Echolocating sperm whales emit usual click sequences $(0.2$ $<$ ICI $<2 \mathrm{~s}$, interclick intervals), interrupted by faster click trains (creaks, ICI $<0.2 \mathrm{~s}$ ) and then silences (Mullins et al., 1988). Sperm whales emit echolocation clicks mostly during the descent and while hunting within the prey layer (Madsen et al., 2002b). Sperm whales within social groups also send stereotyped ICI structure click sequences, called codas (Weilgart, 1990). Male sperm whales may make some other rare vocalizations, called slow clicks (Jaquet et al., 2001; Madsen et al., 2002b). The use of passive acoustics is not only limited to the study of the click rythmics, but it also leads to an understanding of the click production mechanism (Mohl et al., 2003; Thode et al., 2002) and to the reconstruction of sperm whale diving trajectories (Wahlberg, 2002).

New tagging techniques, using depth-meters, hydrophones, accelerometers, and magnetometers, have enabled scientists to gain knowledge of sperm whale behavior. These tags enable scientists to record sperm whale movements together with their acoustic activity (Johnson and Tyack, 2003; Zimmer et al., 2003). Fluking has been measured while sperm whales swim down and resurface (Miller et al., 2004a). Sperm whales maneuvering is measured during the hunting process (Miller et al., 2004b). Such tagging techniques, like passive acoustics, have also lead to the description of the click production mechanism and to the reconstruction of diving trajectories, but with increased levels of precision (Zimmer et al., 2005). 
While the aforementioned tagging techniques provide insight into sperm whale behavior, the technique itself can disrupt or alter the natural tendencies of the tagged mammals. Also the tagging procedure is time consuming and difficult to implement (Madsen et al., 2002a). Because of this, the authors bring forward a passive acoustic technique that will uncover new behavioral information without such shortcomings. Passive acoustics may give results close to those attained using depth-meter/hydrophone tags (Madsen et al., 2002b). The depth (and range) of sound sources can be estimated by using a single hydrophone. This method has been successfully carried out on sperm whales (Thode et al., 2002) and dolphins (Aubauer et al., 2000). Nevertheless, the accuracy on the depth and range measurements is not enough for estimating subtle foraging sperm whale movements.

The authors estimate subtle sperm whale movements by measuring pitch angle variations using a single towed hydrophone. The comparison of these variations to the acoustic activity then leads to a hypothesis on the sperm whale echolocation system: sperm whales, like some other toothed whale species, would control click level and ICI when echolocating on targets at different ranges. The authors then compute an echolocation model estimating sperm whale target ranges from the ICI. They apply this echolocation model during the sperm whale descent and hunt, and assess its consistency. They estimate the water mass geometry analyzed by the whale's sonar during both stages, leading to the hypothesis of a dive-scale sperm whale foraging strategy.

\section{MATERIAL AND METHODS}

\section{A. Single hydrophone localization}

The authors need to assess the vertical distribution of click level to estimate sperm whale pitch angle. To this end, they compare the click levels emitted along different rays of multipath propagating sperm whale clicks. The authors estimate the depth and range of phonating sperm whales, before reconstructing the multipath ray geometry, to measure the attenuation of the click signals when transmitting along these rays.

The sea surface and the seafloor reflect and diffuse propagating acoustic waves (Clay and Medwin, 1977). The hydrophones collect multiple delayed, dephased, and attenuated versions of the signals emitted by sound sources (Fig. 1). The use of a single hydrophone, and the detection of $n$ surface/seafloor echoes, serves as a substitute of a large virtual vertical $(n+1)$-hydrophone array (one real, $n$ virtual) (Aubauer et al., 2000). A sound source can be localized in depth and range from this array, by measuring the time of arrival differences of the source signal between the virtual hydrophones, then by measuring the time of arrival differences between the echoes (Fig. 2). One needs to detect two echoes of a click to estimate the depth and range of a phonating sperm whale. The detection of an additional echo leads to an estimation of the depth of the recording hydrophone (Thode et al., 2002).
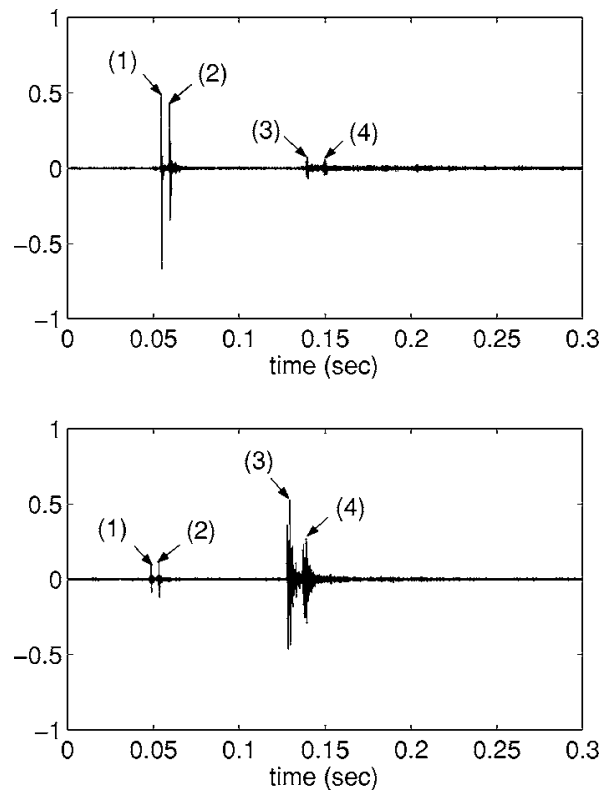

FIG. 1. Signals received from a single emitted sperm whale click. Here, assuming $z_{h}<z_{s}<z_{b}-z_{h}$ (Fig. 2), the direct path click signal (1) comes first, followed by the surface echo (2), the seafloor echo (3), and the-twice reflected seafloor/surface echo (4). Click signals reflected by the seafloor are more attenuated when propagating (by reflecting and by transmitting on a longer distance) than click signals transmitted via direct path. The amplitude of the former may anyway be greater than the amplitude of the latter, suggesting click directionality.

\section{B. Accuracy}

The depth, range, and propagation loss are estimated using a spherical propagation model, by assuming that the speed of sound is constant along the water column. The validity of this convenient hypothesis is assessed by comparing this model with a ray-tracing model. The vertical variations of the speed of sound are estimated from temperature and salinity values given by the MERCATOR oceanic model (MERCATOR, 2004). The authors have compared the propagation times of sperm whale clicks by ray tracing, in a me-

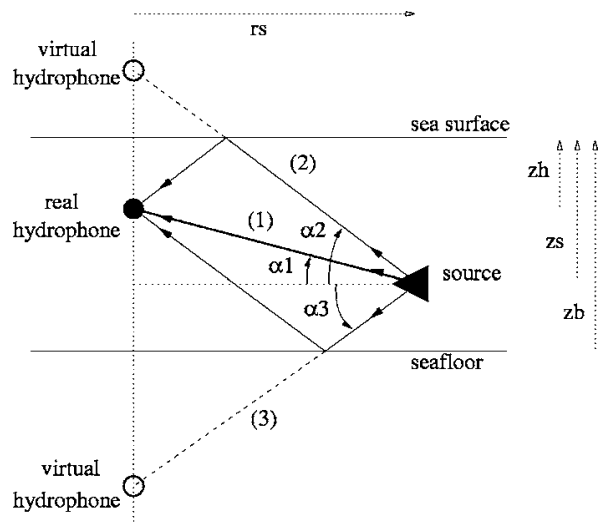

FIG. 2. Multipath ray geometry. The depths of the sperm whale, the hydrophone, and the seafloor are respectively $z_{s}, z_{h}$, and $z_{b}$. The sperm whale is at the range $r_{s}$ from the hydrophone. The direct path ray, surface reflected ray, and seafloor reflected ray form the algebraic angles $\alpha_{1}\left(\alpha_{1}>0 \Leftrightarrow z_{s}>z_{h}\right)$, $\alpha_{2}\left(\alpha_{2}>0\right)$, and $\alpha_{3}\left(\alpha_{3}<0\right)$ to the horizontal. The detection of two surface/ seafloor echoes serves as a substitute of a large virtual vertical hydrophone array of length $2 z_{b}$. The whale depth and range define the geometry of the multipath rays (length and inclination). 
dium of a varying speed of sound, and in a medium of a constant speed of sound. The curvature of the rays has negligible effects on the propagation times (Laplanche et al., 2004). An adjustment of the single hydrophone localization technique (Thode et al., 2002), taking into account speed of sound variations (Laplanche et al., 2004), would indicate that in the context of the author's experiments, the assumption of a spherical propagation model would be enough. This assumption would be valid in some sensible settings, with a hydrophone and a source not too close to the sea surface, and a source at close enough range, so as to limit the interference and refraction phenomena.

The accuracy of the localization process when using the spherical propagation model is evaluated using a random variable error estimator (Laplanche et al., 2004) modeling with Gaussian random variables the nonlinear error estimation method presented in Wahlberg (2004). The source depth and range are calculated from the seafloor depth, the hydrophone depth, the surface/seafloor echo delays, and the mean speed of sound (Thode et al., 2002). A large number of samples (100 000) of these parameters are drawn around a mean (the measured value) with a standard deviation (half the accuracy of the measurement). The accuracies (twice the standard deviations) of the source depth and range are estimated from the depth and range samples calculated from the parameter samples. The linearity of the localization process is evaluated by estimating the kurtosis excess of the depth and range samples.

\section{Click level}

Acoustic waves are attenuated when propagating in the sea water and when reflecting on the sea water interfaces. Still using the spherical propagation model, the attenuation of an acoustic wave when traveling through a distance $r$ of sea water is close to $20 \log _{10}(r)+a r$ (Aubauer et al., 2000). The absorption coefficient $a$ depends on the frequency of the transmitting wave and on chemical properties of the sea water (such as $p \mathrm{H}$, salinity, and temperature). In this particular case, it is close to $a=10^{-3} \mathrm{~dB} / \mathrm{m}$ using the Thorp model. The authors consider sperm whale click central frequency at $9 \mathrm{kHz}$, given the limited band of the recording system, as compared to the $15-\mathrm{kHz}$ sperm whale click central frequency (Madsen et al., 2002a).

The attenuation of an acoustic wave when reflecting to the seafloor is estimated using the Hall-Watson model. It is contingent upon the incidence angle of the wave on the seafloor, the frequency of the wave, and the porosity $(0<p$ $<1$ ) of the seafloor.

Using the sonar equation, the measurement of the input levels, and the estimation of the propagation attenuation of direct path transmitted sperm whale click signals and seafloor reflected click signals will then lead to an evaluation of the apparent source levels of the clicks in these ray directions (in $\mathrm{dB}$ re: $1 \mathrm{~V} / \mu \mathrm{Pa}$ ). The comparison of the apparent source levels in these ray directions will then lead to an estimation of the vertical distribution of the click beam energy.

\section{Sperm whale pitch angle variations}

Let us consider a sperm whale at a depth $z_{s}$ and a range $r_{s}$ from a hydrophone, itself at a depth $z_{h}$, in a basin of depth $z_{b}$ (Fig. 2). The direct path ray (1), the surface echo ray (2), and the seafloor echo ray (3) form the algebraic angles to the horizontal $\alpha_{1}=\operatorname{atan}\left[\left(z_{s}-z_{h}\right) / r_{s}\right], \quad \alpha_{2}=\operatorname{atan}\left[\left(z_{s}+z_{h}\right) / r_{s}\right]$, and $\alpha_{3}=\operatorname{atan}\left[\left(z_{s}+z_{h}-2 z_{b}\right) / r_{s}\right]$. Let $p_{1}, p_{2}$, and $p_{3}$ be sperm whale click level sent in these three directions. The ratios $\left(p_{i} / p_{j}\right)_{\mathrm{dB}}=20 \log _{10}\left(p_{i} / p_{j}\right)$ would lead to an estimation of the vertical click level distribution.

Sperm whales may alter the click level while diving, as discussed below. There would be no consequences of click level variations on the values of the ratios $\left(p_{i} / p_{j}\right)_{\mathrm{dB}}$, if the sperm whale click frequency content were constant. But sperm whales, like smaller odontocetes, alter jointly click frequency and level (Madsen et al., 2002a). Such a frequency emphasis would lead, after transmission, to an alteration of the measurement of the ratios $\left(p_{i} / p_{j}\right)_{\mathrm{dB}}$, and a resulting bias in the estimation of the sperm whale pitch angle. The authors, given the limited band of their recording system, assume these effects to be negligible. Directionality variations, as directly induced by a modification of the shape of the click beam, would also alter the whale pitch angle estimation. However, such variations do not take place, as discussed below. The variations of the ratio $\left(p_{i} / p_{j}\right)_{\mathrm{dB}}$ would then be representative of a change in the direction the sperm whale click beam.

The surface ray is directed upwards $\left(\alpha_{2}>0\right)$, and the seafloor ray is directed downwards $\left(\alpha_{3}<0\right)$. The upwards/ downwards direction of the direct ray (Fig. 2) depends on the depth of the source $\left(\alpha_{1}>0 \Leftrightarrow z_{s}>z_{h}\right)$. For short cable surface hydrophones $\left(z_{h} \ll z_{b}\right)$, the direct ray would be directed upwards, as sperm whales usually start clicking a few minutes after beginning a dive, stop clicking a few minutes before surfacing, and are usually silent at the sea surface level (Whitehead and Weilgart, 1990). For short cable hydrophones mounted on the seafloor $\left(z_{b}-z_{h} \ll z_{b}\right)$, the direct ray would be directed downwards. For long cable hydrophones, a preliminary source localization is necessary to conclude the direction of the ray. One can demonstrate that the aperture angles defined by the direct/surface rays and the seafloor ray are greater than $\pi / 4$ for a usual source range/depth setting, $\alpha_{1}-\alpha_{3} \geqslant \pi / 4$ for $r_{s} \leqslant 2\left(z_{b}-z_{h}\right)$ and $z_{s}>z_{h}, \alpha_{2}-\alpha_{3} \geqslant \pi / 4$ for $r_{s} \leqslant 2 z_{b}$ and $z_{s}>z_{h}$.

The ratio $\left(p_{2} / p_{3}\right)_{\mathrm{dB}}$ [or $\left(p_{1} / p_{3}\right)_{\mathrm{dB}}$, assuming a short cable surface hydrophone] would then assess the trend in the vertical direction of the click energy. Assuming a vertical symmetry of the sperm whale click acoustic beam (Zimmer et al., 2005), then $p_{2} / p_{3}=0 \mathrm{~dB}$ for clicks emitted in the direction $\left(\alpha_{2}+\alpha_{3}\right) / 2, p_{2} / p_{3}>0 \mathrm{~dB}$ for clicks emitted in directions $\alpha>\left(\alpha_{2}+\alpha_{3}\right) / 2$, and $p_{2} / p_{3}<0 \mathrm{~dB}$ for clicks emitted in directions $\alpha<\left(\alpha_{2}+\alpha_{3}\right) / 2$. For $\left|\alpha_{2}\right| \simeq\left|\alpha_{3}\right|$, the sign of $\left(p_{2} / p_{3}\right)_{\mathrm{dB}}$ gives the vertical direction of the click beam. Assuming that sperm whales need to move their head to change the direction of the click beam, the variations of $\left(p_{2} / p_{3}\right)_{\mathrm{dB}}$ would then indicate changes in sperm whale vertical movement. The authors define the whale pitch angle $\beta$ as the angle formed by the whale's dorso-rostral axis and the horizontal. 


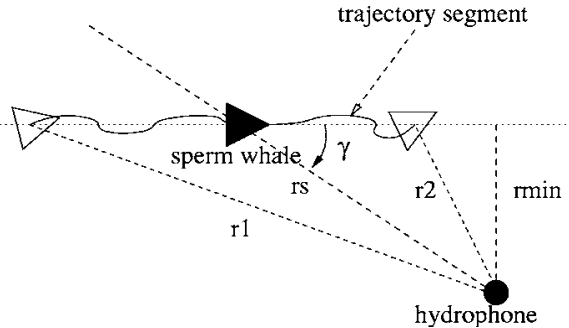

FIG. 3. Sperm whale trajectory. The sperm whale trajectory is deconstructed into segments (here a single segment, projected into the horizontal plane), the whale moving straight at constant speed in each segment. In this example, the whale moves along the segment from the range $r_{1}$ at $t_{1}$ to the range $r_{2}$ at $t_{2}$. The range of the whale while crossing the segment is $r_{s}=\sqrt{r_{\min }^{2}+v_{r}^{2}\left(t-t_{\min }\right)^{2}}$, and its heading is defined by the angle $\gamma$. The range $r_{\min }$ is the horizontal distance of the segment to the hydrophone. $t_{\min }$ is the time the whale passes (or would pass) at the range $r_{\min }$.

\section{E. Sperm whale pitch angle}

The use of a sperm whale click beam pattern (Zimmer et $a l ., 2005)$ theoretically leads to a quantification of the values of sperm whale pitch angles. Using a whale heading to the direction $\gamma$ (defined as the projection of the off-axis angle on the horizontal plane, Fig. 3) with the pitch angle $\beta$, a trigonometry calculation leads to the value of the off-axis angle $\delta$ of the hydrophone to the whale click beam:

$$
\cos \delta=\cos \alpha_{1} \cos \beta \cos \gamma+\sin \alpha_{1} \sin \beta .
$$

And by defining $\zeta \in]-\pi / 2, \pi / 2[$ such that $\tan \zeta$ $=\cos \gamma / \tan \alpha_{1}$, the whale pitch angle can be calculated from the off-axis angle, by selecting $\beta \in[-\pi / 2, \pi / 2]$ from

$$
\begin{aligned}
& \beta=\operatorname{asin}\left(\frac{\cos \delta \cos \zeta}{\sin \alpha_{1}}\right)-\zeta \text { or } \\
& \beta=\pi-\operatorname{asin}\left(\frac{\cos \delta \cos \zeta}{\sin \alpha_{1}}\right)-\zeta .
\end{aligned}
$$

Using the sperm whale click beam pattern and the estimation of the click gain, the estimation of the click beam level emitted towards the hydrophone leads to the estimation of the ray off-axis angle $\delta$, which then leads to an estimation of the whale pitch angle $\beta$. The sperm whale heading $\gamma$ is estimated from the three-dimensional whale trajectory, as described below.

\section{F. Sperm whale trajectory reconstruction}

The authors estimate small scale sperm whale pitch movements from the vertical distribution of click level. Large scale movements can be estimated from the sperm whale depth and range estimations, which are found by measuring click echo delays. Large scale movements will give an estimation of the sperm whale heading $\gamma$, as required in the sperm whale pitch angle quantification process. Large scale movement will also lead to the rough three-dimensional reconstruction of sperm whale trajectories.

The authors deconstruct the sperm whale trajectory into segments, while assuming a uniform sperm whale movement (straight and at constant speed) on each segment. Let us consider a whale at depth $z_{1}$, range $r_{1}$, and time $t_{1}$ heading straight to reach the depth $z_{2}$, range $r_{2}$, and time $t_{2}$ at the constant speed $v_{12}$ (Fig. 3). The sperm whale depth and range at a time $t_{1} \leqslant t \leqslant t_{2}$ are

$$
\begin{aligned}
& z_{s}=z_{1}+v_{z}\left(t-t_{1}\right), \\
& r_{s}^{2}=r_{\text {min }}^{2}+v_{r}^{2}\left(t-t_{\text {min }}\right)^{2},
\end{aligned}
$$

while the vertical and horizontal speeds of the whale are

$$
\begin{aligned}
& v_{z}=\left(z_{2}-z_{1}\right) /\left(t_{2}-t_{1}\right), \\
& v_{r}=\sqrt{r_{1}^{2}-r_{\min }^{2}} /\left(t_{1}-t_{\min }\right),
\end{aligned}
$$

where $r_{\min }$ is the horizontal distance of the hydrophone to the line containing the trajectory segment, and $t_{\min }$ is the time when the whale would reach the range $r_{\text {min }}$ (Fig. 3). Interpolating the whale depth variations during $\left[t_{1}, t_{2}\right]$ with a straight line leads to an estimation of depths $z_{1}, z_{2}$ and vertical speed $v_{z}$. Interpolating the squared whale range variations $r_{s}^{2}$ with a parabola leads to an estimation of the ranges $r_{1}, r_{2}$, $r_{\min }$ and the horizontal speed $v_{r}$. Such interpolations lead to an estimation of the three-dimensional geometry of the trajectory segment (a symmetry and a rotation around the hydrophone vertical axis apart), the whale speed $v_{12}=\sqrt{v_{z}^{2}+v_{r}^{2}}$, and the whale heading $\gamma$ when crossing this segment (Fig. 3).

\section{G. Recording system}

The data were recorded during two missions in the Mediterranean Sea, in the Main Channel of the Strait of Gibralter in March 2003, and in the abyssal plain offshore Toulon in August 2004, using preamplified, omnidirectional, ceramic Vinci-Technologies HC2000 hydrophones, with an output sensitivity of, $-155 \mathrm{~dB}$ re: $1 \mathrm{~V} / \mu \mathrm{Pa}$, and a frequency response flat in the frequency window $[80 \mathrm{~Hz}, 13 \mathrm{kHz}]$. The signals were sampled at $44.1 \mathrm{kHz}, \mathrm{PCM}$ coded with 16 bits using a laptop with a Digigram VXpocket 440 soundcard, and recorded using the multitrack software Sek'd Samplitude. In this experiment, the signals have been highpassed at $3 \mathrm{kHz}$ with a digital filter, so as to enhance the $\mathrm{S} / \mathrm{N}$ ratio in the click detection process, given the relative frequency bands of sperm whale clicks and background noise. Solitary male sperm whales were recorded, from the CIRCé ship Elsa $(10 \mathrm{~m})$ during the 2003 mission, and from three Breach sail boats Brin d'alu (10 m), Saoufe (12 m), and Zino (14 m) during the 2004 mission.

Hydrophones were at 30-m depth in 2003 and $70 \mathrm{~m}$ in 2004. The sea bottom was at $900 \mathrm{~m}$ in 2003 and $2000 \mathrm{~m}$ in 2004. The depth of the seafloor was measured using marine charts and is defined as the depth below the hydrophones. The depth of the hydrophones $z_{h}$ was estimated using the method presented in Thode et al. (2002). The seafloor is assumed to be flat at a known depth and of known porosity. The assumption of a flat seafloor is applicable in the author's examples but not in all other cases. When sperm whales are recorded in front of the continental slope, clicks reflect on the cliff into many echoes, making difficult their identification. The clear detection of seafloor echoes is a good test for substantiating the flatness of the seafloor. In both recording locations cited above, the seafloor was flat enough to identify 


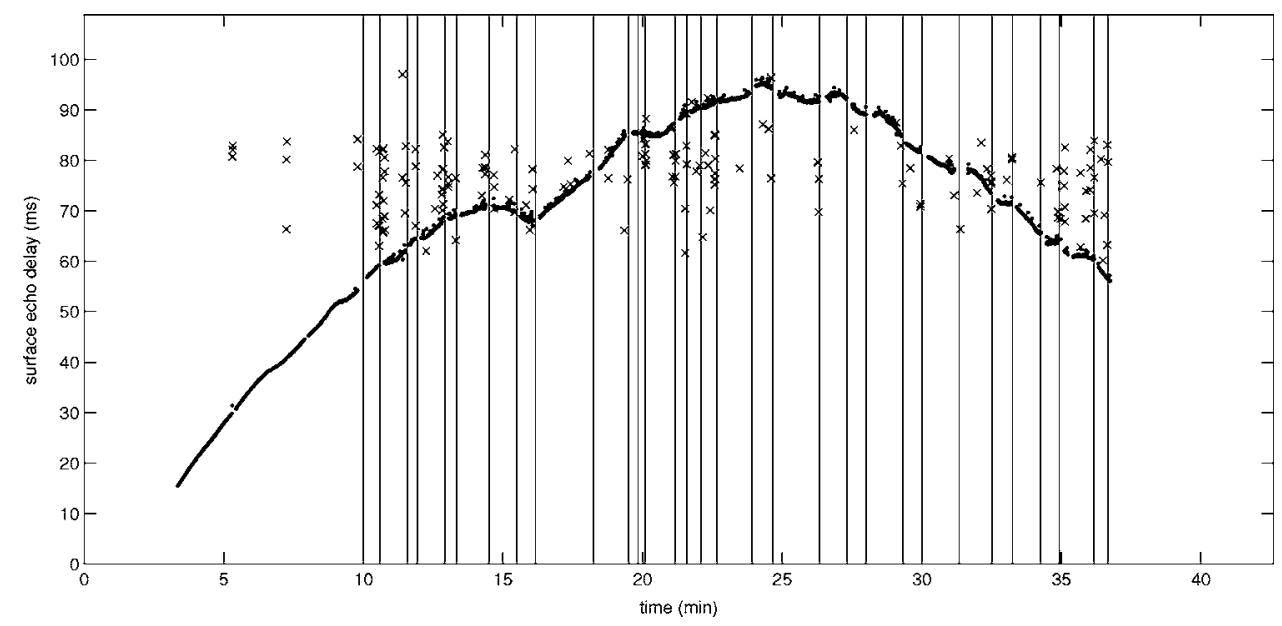

FIG. 4. Surface echo delay variations during a complete dive. A whale (2004 data set) emitted 2380 usual clicks and 31 creaks (vertical lines) during a 45-min dive. Two thousand clicks are detected using a threshold/crosscorrelation algorithm, leading to 2000 measurements of the surface echo delay (dots). The algorithm wild points are also plotted (200, crosses). The whale emitted the first creak at $t$ $=10 \mathrm{~min}$, at the depth $z_{b}=400 \mathrm{~m}$, with a 57-ms surface echo delay. The whale repeats 31 search/terminal phases, in this example ending with creaks.

the detected echoes. Short-scale relief variations scatter seafloor echoes and decrease the accuracy of the measurement of their delays. The consequence of this lack of accuracy is estimated using the random variable error estimation method described above.

\section{H. Delay/level measurements}

The data is recorded from isolated male sperm whales. The authors study the acoustic behavior of isolated male sperm whale individuals and do not deal with group strategies. The methods (click detection) and results would apply within this framework. Nevertheless, hypotheses on the acoustic behavior of isolated sperm whales could also help in understanding the behavior of each individual within a group.

Surface echoes are always detected jointly with direct path click signals. Twice reflected seafloor/surface echoes are also always detected with once-reflected seafloor echoes (Fig. 1). Seafloor echoes are well detected during the first 10 min of dives, when sperm whales vertically swim down and echolocate towards the seafloor (Thode et al., 2002). The seafloor echo detection during the hunting stage depends on the seafloor properties (depth and relief) and the whale range. The seafloor echoes were more easily detected during the 2003 mission, by recording sperm whales from a longer range in a more shallow bassin. Surface and seafloor echo delays are measured by cross-correlating the echoes with the direct path signal. The localization and click level measurement processes have been automated by estimating the $a$ priori probability density functions of the surface/seafloor delays as described in Laplanche et al. (2005).

\section{RESULTS}

\section{A. Acoustic behavior}

The variations of the surface echo delay during a complete dive of a single sperm whale (recorded during the 2004 mission) are plotted in Fig. 4. The whale emitted 2380 usual clicks and 31 creaks. The additional detection of seafloor echoes at the beginning of the dive leads to the plotting of the sperm whale depth and range variations which indicate a vertical dive, as illustrated by Madsen et al. (2002a) and Thode et al. (2002). The ICI variations during the descent are plotted in Fig. 5.

After vertically diving to $400 \mathrm{~m}$, the whale repeats an acoustic pattern lasting between 30 and $180 \mathrm{~s}$, composed of a block of usual clicks, hereafter referred to as search phase, ending with a creak or a pause, hereafter referred to as terminal phase. Such a notation, used by different authors regarding Blainville's beaked whales (Madsen et al., 2005), is discussed below. Some of these search/terminal phases are plotted in Fig. 6. Usual click sequences during search phases (as described below) are not always such stereotypes, but similar patterns were found in 2003 and 2004. Creaks are not always emitted during the terminal phases (Madsen et al., 2002 b). If no creaks were detected in 2003, every search phase ended with a creak in 2004. And silences are also sometimes skipped during the terminal phases (Mullins et al., 1988).

\section{B. Click directionality and level}

The estimated direct path and seafloor reflected click levels ( $p_{1}$ and $p_{3}$, respectively) and ICI variations during search/terminal phases are plotted in Fig. 6. Here, the whale is located at a depth $z_{s}=600 \pm 30 \mathrm{~m}$ (kurtosis excess 3 $\times 10^{-3}$ ), and a range $r_{s}=3700 \pm 250 \mathrm{~m}$ (kurtosis excess 2 $\times 10^{-3}$ ), from a hydrophone at a depth $z_{h}=32 \pm 2 \mathrm{~m}$, in a basin of depth $z_{b}=880 \pm 30 \mathrm{~m}$ and mean speed of sound $c_{0}$ $=1512 \pm 10 \mathrm{~m} / \mathrm{s}$, measuring surface echo delays $\pm 0.1 \mathrm{~ms}$ and seafloor echo delays $\pm 0.5 \mathrm{~ms}$. The direct ray, the surface ray, and the seafloor ray then create respectively $\alpha_{1}=8.5 \pm 0.6$, $\alpha_{2}=9.5 \pm 0.6$, and $\alpha_{3}=-17 \pm 1.3$ (kurtosis excess $5 \times 10^{-2}$ ) degree angles with the horizontal (Fig. 2). The $0 \mathrm{~dB}$ value of the level ratio $\left(p_{1} / p_{3}\right)_{\mathrm{dB}}$ would then correspond to a click emitted slightly downwards, forming a $\alpha=\left(\alpha_{1}+\alpha_{3}\right) / 2$ $=-4.2^{\circ} \pm 0.6^{\circ}$ angle with the horizontal.

The sperm whale click beam pattern is extremely narrow $\left[\left(p_{1} / p_{3}\right)_{\mathrm{dB}}=-30\right.$ at $t=780 \mathrm{~s}$, Fig. 6]. Sperm whale clicks are also very powerful (Fig. 7), reaching $210 \mathrm{~dB}$ re: $1 \mu \mathrm{Pa}$ (pp) (limiting to the band $[3 \mathrm{kHz}, 13 \mathrm{kHz}]$ ). These two results are consistent with previous findings, i.e., the sperm whale click generator can also serve as an echolocation system (Mohl et al., 2003). 

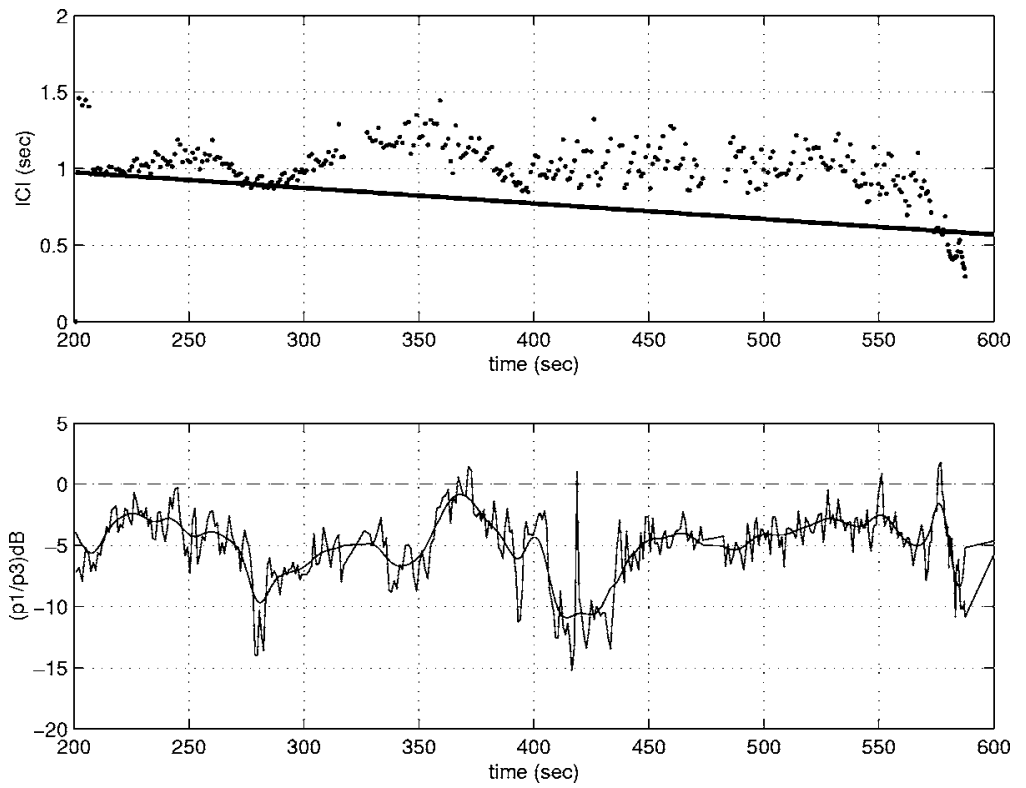

FIG. 5. ICI and pitch angle variations during the descent. ICI during the first $10 \mathrm{~min}$ of a dive (dots, at the top). Using the echolocation model, the estimated ICI during the descent, when using targets vertically below the whale inside the prey layer, is also plotted (solid line). The pitch angle variations are plotted [ratio $\left(p_{1} / p_{3}\right)_{\mathrm{dB}}$, raw values and moving average, at the bottom]. The bissecting angle [for which $\left(p_{1} / p_{3}\right)_{\mathrm{dB}}=0$ ] between the direct ray and the bottom ray varies from $-39^{\circ} \rightarrow-27^{\circ}$ to the horizontal for $t=200 \rightarrow 600 \mathrm{~s}$. The whale pitch angle is then greater than $30^{\circ}$ during the descent $\left[\right.$ as $\left.\left(p_{1} / p_{3}\right)_{\mathrm{dB}}<0\right]$. The ICI variations are correlated to the pitch angle variations. Pitch angle variations suggest a three-phase pitch movement $((t=200 \rightarrow 250$ $\rightarrow 280 \mathrm{~s}, t=280 \rightarrow 350 \rightarrow 400 \mathrm{~s}, t=400 \rightarrow 480 \rightarrow 570 \mathrm{~s})$. The ICI plotting ends $([580,600] \mathrm{s})$ with the first search phase inside the prey layer.

\section{Sperm whale movements}

In this study, only relative (and not absolute) values of sperm whale pitch angles are estimated, by using the ratio $\left(p_{1} / p_{3}\right)_{\mathrm{dB}}$. The complexity of the sperm whale click beam pattern as formed by various components of different levels and frequency contents (Zimmer et al. 2005), the lack of knowledge in the variations amongst sperm whale individuals of this click beam pattern, the lack of knowledge in the click level variations, and the use by the authors of a limited bandwith recording system kept the authors from conducting a reliable pitch angle quantification process [using Eq. (2)].

Sperm whale pitch angle variations are plotted during a descent (Fig. 5) and during two successive search/terminal phases (Fig. 6). The respective acoustic activity is also plotted. The sperm whale pitch movements go together with the rhythmic variations while descending (Fig. 5). The sperm whale pitch movements while hunting are periodic and in sync with the rhythmic variations (Fig. 6). In the next section, the authors propose a hypothesis on the sperm whale biosonar, so as to clarify this correlation between the sperm whale acoustical and physical activity.

\section{DISCUSSION}

\section{A. Echolocation model}

The recorded sperm whales emitted bursts of usual clicks each lasting 5-15 s during the search phases, followed by clicks at a higher rate (creaks) and/or silence periods during the terminal phases (Fig. 6). As shown in Fig. 7, during the search phase, clicks from a burst are first emitted every $\mathrm{ICI}_{\max }$ second. The interclick interval then progressively decreases to $\mathrm{ICI}_{\min }$, before gradually increasing to a new maximum $\mathrm{ICI}_{\max }^{\prime}$. These variations of the interclick interval are correlated to those of the levels $p_{1}$ and $p_{3}$ of the direct path/seafloor reflected click signals. During the search phases, 20-dB level peaks are simultaneously detected in both direct path and seafloor path directions. Such peaks were only detected when recording from directions close to the whale axis, as discussed below. Click level maximums $p_{\max }$ emitted towards these paths are detected when the interclick interval of a 5-15-s burst reaches its maximum $\mathrm{ICI}_{\max }$. And click level minimums $p_{\min }$ are detected when the interclick interval reaches its minimum $\mathrm{ICI}_{\min }$ (Fig. 7).

Four hypotheses could explain such apparent click level
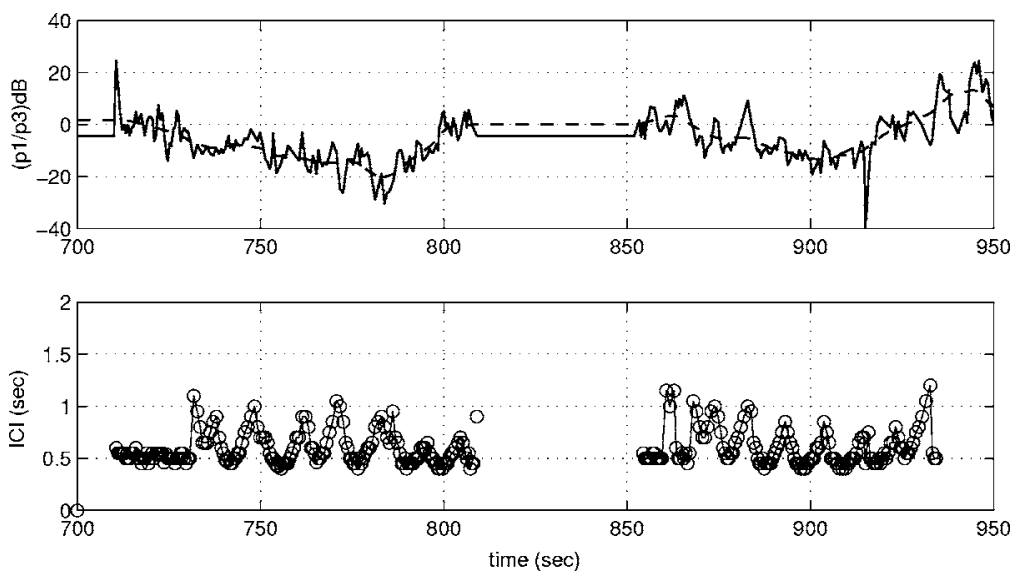

FIG. 6. Sperm whale pitch angle and ICI during two successive search/terminal phases. Relative sperm whale pitch angle $\left(p_{1} / p_{3}\right)_{\mathrm{dB}}=20 \log _{10}\left(p_{1} / p_{3}\right)$ (solid line) and moving average (dashed line, at the top). It is positive for clicks emitted upwards, and negative for click emitted downwards. ICI (at the bottom). 

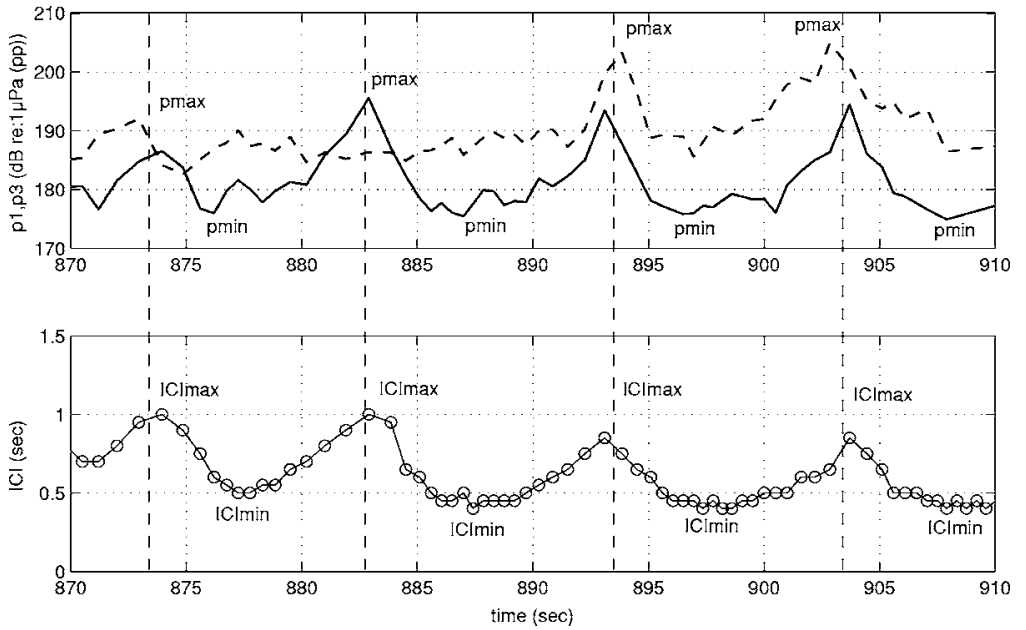

FIG. 7. Sperm whale click level and ICI during a search phase. (Top) Click source level $p_{1}$ emitted (upwards) towards the direct path (solid line), and click source level $p_{3}$ emitted (downwards) towards the seafloor reflected path (dashed line). (Bottom) ICI. Peaks of source level in $p_{1}$ and $p_{3}$ are detected when the sperm whale clicks at the lowest rate $\left(\mathrm{ICI}=\mathrm{ICI}_{\max }\right)$, and minimum values of level are detected when the sperm whale clicks at the highest rate $\left(\mathrm{ICI}=\mathrm{ICI}_{\min }\right)$. The difference of click level within a click burst may reach $20 \mathrm{~dB}$. variations: vertical movement of the sperm whale head (pitch), horizontal movement (yaw), click directionality control, and click level control. The first hypothesis is rejected given the pitch angle variations plotted in Fig. 6. The second hypothesis is rejected, as maximums/minimums of click levels are always in sync with maximums/minimums of ICI (this also applies to the first hypothesis). The whale would have to systematically direct its click beam towards the hydrophone when clicking at a slow rate, and turn its head when clicking faster, which is highly unlikely. The third hypothesis would suggest that sperm whales would emit highly directional clicks when clicking fast, and widen the click beam when clicking slower. The fourth hypothesis would suggest that sperm whales would send less powerful clicks when clicking fast, and increase the click level when clicking slower. Homogenous off-axis angle variations of a measured sperm whale click beam pattern (Zimmer et al. 2005) would suggest that sperm whales would not change the click directionality when diving. The variations in click level given in Fig. 7 would rather suggest click level control.

These click level variations are in sync with the ICI variations, suggesting click level and ICI adjustment to the target range, as found on some smaller odontocetes, as discussed below. Yet some sperm whale tag recordings show no correlation between click level and ICI variations (Madsen et al., 2002a). Click level variations as plotted in Fig. 7 were not detected when making off-axis recordings (especially in 2004, when recording from a shorter range). The authors then suggest that these level variations would only appear, using Mohl et al. (2003) notation, on the forward echolocation pulse $\left(P_{1}\right)$. The initial backward pulse $\left(P_{0}\right)$ level would not be altered by this process. Off-axis recordings, from a distant towed hydrophone or a tag attached to the whale's back, would then not detect the click level variations as plotted in Fig. 7. Still, what would explain $P_{0} 20-\mathrm{dB}$ level variations detected from the tags (Madsen et al., 2002a)? Would click level adjustment to target range take place while transmitting within the nasal complex, and a different click level adjustment (to target kind?) take place when emitting the initial pulse at the phonic lips? Understanding click level variations may be a key point in learning the workings of the sperm whale's biosonar. The hypothesis on click level (and
ICI) control to target range would lead to sensible results, as discussed below, and provide some clues regarding the understanding of the sperm whale's biosonar.

Results from biosonar tests carried out on some smaller odontocetes suggest click level control (Au and Herzing, 2003; Au and Wursig, 2004; Rasmussen and Miller, 2002) with target range. Dolphins would adjust the click level by $6 \mathrm{~dB}$ for every halved or doubled target range. ICI control has also been observed on bottlenose dolphins (Au, 1993). Such an acoustic behavior does not seem to be characteristic of all ondontocete species (Madsen et al., 2005). The sperm whale's and dolphin's biosonar share many similarities (Madsen et al., 2002a), and, given measurements illustrated in Fig. 7, it would be interesting to assess the consistency of the hypothesis of click level and ICI control to target range on sperm whales.

The author's echolocation model speculates that sperm whales control click level and ICI to target range as bottlenose dolphins do. The click level variations presented in Fig. 7 would then result in adjustments by $6 \mathrm{~dB}$ for every halved or doubled target range. The ICI would directly depend on the whale's target range $r, \mathrm{ICI}=2 r / c_{0}+t_{\text {proc }}(\mathrm{Au}, 1993)$. The constant processing delay $t_{\text {proc }}$ would be the delay between the reception of the echo of a click and the production of the next click.

\section{B. Processing delay}

Sperm whales would adjust the level of clicks to compensate for the one-way transmission loss between the whale and its target. If a click emitted with a $0-\mathrm{dB}$ gain aims at a target at a range $r$, a click emitted with a gain $G(\mathrm{~dB})$ would then aim at a target at a range $10^{G / 20} r$, assuming only spherical spreading loss. Then, by labeling $r_{\max }$ and $r_{\min }$ the range of the targets aimed using clicks at the rates $1 / \mathrm{ICI}_{\max }$ and $1 / \mathrm{ICI}_{\min }$, one arrives at $r_{\max }=10^{G / 20} r_{\min }$ with $G=20 \mathrm{~dB}$, leading to

$$
r_{\max } \simeq \alpha r_{\min } \text { with } \alpha=10 .
$$

Assuming a processing time $t_{\text {proc }}$ of the click echoes independent of the range of the target, then 


$$
\mathrm{ICI}_{\text {min }}=\frac{2 r_{\text {min }}}{c_{0}}+t_{\text {proc }} \text { and } \quad \mathrm{ICI}_{\max }=\frac{2 r_{\max }}{c_{0}}+t_{\text {proc }},
$$

leading to

$$
t_{\text {proc }}=\frac{\alpha \mathrm{ICI}_{\min }-\mathrm{ICI}_{\max }}{\alpha-1} .
$$

From the ICI values given for the first plotted 5-15-s click burst $\left(\mathrm{ICI}_{\max }=1 \mathrm{~s}\right.$ and $\mathrm{ICI}_{\min }=0.5 \mathrm{~s}$ ) (Fig. 7), one can find the processing delay $t_{\text {proc }}=0.45 \mathrm{~s}$. This value would be equal to the minimum ICI corresponding to the shortest target echolocation range $(r=0)$. This value $\mathrm{ICI}=0.45 \mathrm{~s}$ would set the limit of validity of the sperm whale echolocation model described above. The same 0.45 -s value has been found in a statistical analysis, setting the limit between usual clicks and creaks (Zimmer et al., 2005). Sperm whale acoustic activity then splits into two distinct modes, usual clicking (ICI $\geqslant 0.45 \mathrm{~s}$ ) and creaking (ICI $<0.45 \mathrm{~s}$ ), in view of the temporal pattern of the click sequences (search phase/terminal phase), the click rate production (Zimmer et al., 2005), and the echolocation model limit. The delay $t_{\text {proc }}$ has been defined as the delay between the reception of the echo of a click and the production of the next click. It may be interpreted as the sum of the processing delay of the first click target echo, and the delay required to produce the next click. The distinction between usual clicks and creaks mentioned above would then suggest that sperm whales would either process usual click and creak echoes differently, or produce usual clicks and creak clicks differently.

The echolocation model is now calibrated by estimating $t_{\text {proc }}=0.45 \mathrm{~s}$. Its consistency is then evaluated during sperm whale descent and hunting.

\section{Scan during the descent}

Sperm whales emit echolocation clicks during most of the descent. What do they echolocate? Some authors have suggested that sperm whales echolocate to the sea floor. ICI variations are indeed correlated to the whale depth variations and consistent with a vertical scan of the sea bottom (Thode et al., 2002). The authors have in this case used the echolocation model ICI $=2 r / c_{0}$, close to the one presented here but with a null processing delay. The seafloor scanning hypothesis, however, would not seem to be correct. Different authors have shown that the ICI of click sequences emitted during the descent may sometimes be much shorter than the two-way travel time to the sea bottom (Zimmer et al., 2005). These authors have suggested that sperm whales rather scan their prey layer while descending. ICI variations during the descent are indeed correlated to whale pitch angle variations (Zimmer et al., 2003).

The authors apply the echolocation model $\mathrm{ICI}=2 r / c_{0}$ $+0.45 \mathrm{~s}$ to the descent. Pitch variations correlated to ICI variations are also noticed using the method presented by the authors (Fig. 5). The authors assess the consistency of the aforementioned hypothesis of prey layer scanning while descending. In the example of Fig. 4, the prey layer is at $400 \mathrm{~m}$, which is equal to the depth of the sperm whale when emitting the first creak. Using the echolocation model, the estimated ICI during the descent, when using targets vertically below the whale inside the prey layer, is plotted in Fig. 5. Measured and estimated ICIs are equal at $t=200,280$, 400 , and $570 \mathrm{~s}$. The measured ICI is greater than the estimation between these instants; it increases for $t=200 \rightarrow 250 \mathrm{~s}$, $t=280 \rightarrow 350 \mathrm{~s}$, and $t=400 \rightarrow 480 \mathrm{~s}$; and decreases for $t$ $=250 \rightarrow 280 \mathrm{~s}, t=350 \rightarrow 400 \mathrm{~s}$, and $t=480 \rightarrow 570 \mathrm{~s}$. These variations are correlated to those of the estimated pitch angle (Fig. 5). This would suggest, as mentioned in Zimmer et al. (2003), that the sperm whale indeed echolocated vertically at the prey layer (at $t=200,280,400 \mathrm{~s}$ ), and echolocated at a horizontal prey layer strip by a vertical movement of its body while descending. The sperm whale pitch angle and the prey layer strip geometry can be quantified using the echolocation model. The sperm whale would start echolocating vertically, and make three scans of the prey layer, with pitch angles varying to $90^{\circ} \rightarrow 60^{\circ} \rightarrow 90^{\circ}$ for $t=200 \rightarrow 250 \rightarrow 280 \mathrm{~s}, 90^{\circ}$ $\rightarrow 30^{\circ} \rightarrow 50^{\circ}$ for $t=280 \rightarrow 350 \rightarrow 400 \mathrm{~s}$, and $50^{\circ} \rightarrow 20^{\circ}$ for $t=400 \rightarrow 570 \mathrm{~s}$, before entering the prey layer and hunting. Such pitch estimations are consistent with those found using digital tags (Zimmer et al., 2003). The prey strip is estimated as $600 \mathrm{~m}$ long (from the whale pitch angle and distance to the prey layer) and $80 \mathrm{~m}$ deep (from the whale pitch angle and its ICI standard deviation). The results presented in this section would suggest that sperm whales would indeed echolocate at their prey layer while descending, and follow an acoustic behavior which would be close to the aforementioned echolocation model.

\section{Whale heading}

The authors then estimate the whale trajectory from the interpolation of the whale range variations between $t_{1}$ $=16 \mathrm{~min}$ and $t_{2}=37 \mathrm{~min}$ (Fig. 8). Such variations of the whale range could be explained assuming a straight trajectory at a constant speed, as described above. Based on this hypothesis, the whale would move, in the example of Fig. 8, in a straight line at $v_{r}=0.8 \mathrm{~m} / \mathrm{s}$ from the range $r_{1}=480 \mathrm{~m}$ to the range $r_{2}=650 \mathrm{~m}$, passing at $t_{\mathrm{min}}=25 \mathrm{~min}$ at the minimum range $r_{\min }=200 \mathrm{~m}$. The whale would then swim at a constant heading within the prey layer. Such behavior is consistent with surface visual observations, describing a general constant heading movement of male sperm whales based on the location of the surface breathing points (Watkins et al., 1999). The authors' measurements would support the hypothesis of a sperm whale broken-line trajectory, whereas trajectory reconstructions using tagged accelerometers would support more chaotic underwater behavior (Zimmer et al., 2005). The straightforward movement pointed out by the authors is a large scale movement and does not prevent short scale chaotic movements when closing on prey (Miller et al., 2004a).

\section{E. Scan during the hunt}

Sperm whales would move straightforward while hunting within the prey layer. The whale's physical activity while crossing the prey layer is estimated from the pitch angle variations, as described below. Its acoustic activity and the 


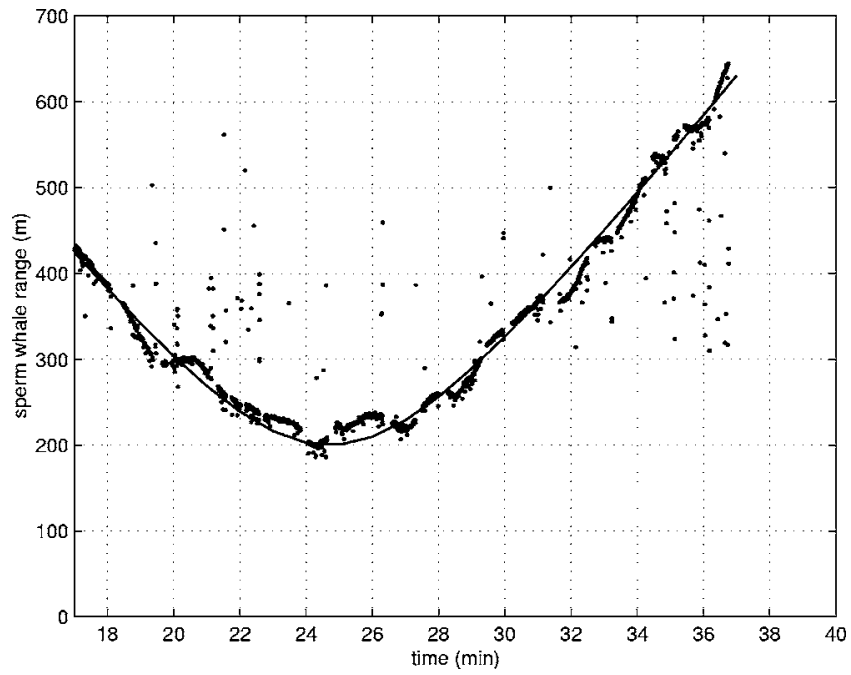

FIG. 8. Sperm whale trajectory reconstruction. Sperm whale range variations (dots) and parabola interpolation (solid line) between $t_{1}=16 \mathrm{~min}$ and $t_{2}=37 \mathrm{~min}$. The whale would move in a straight line at $v_{r}=0.8 \mathrm{~m} / \mathrm{s}$ from the range $r_{1}=480 \mathrm{~m}$ to the range $r_{2}=650 \mathrm{~m}$, passing at $t_{\min }=25 \mathrm{~min}$ at the minimum range $r_{\min }=200 \mathrm{~m}$.

range of the whale's targets are estimated from the ICI using the echolocation model. The conjunction of all these bits of information would lead to the authors' hypothesis asserting that sperm whales would methodically scan a cone-shaped water mass searching for prey with usual clicking at depth. Sperm whales would then attack while silencing or creaking. This methodic scan is a hypothesis, and a consequence of the assessed assumption that sperm whales control ICI when searching for their prey.

The sperm whale's physical activity is estimated from the pitch angle variations (Fig. 6). In this example, the sperm whale would start usual clicking aiming horizontally $\left(p_{1} / p_{3}=0 \mathrm{~dB}\right)$. It would then progressively point downwards $\left(p_{1} / p_{3}<0 \mathrm{~dB}\right.$, decreasing), before gradually (but more quickly) coming back to a horizontal line $\left(p_{1} / p_{3}<0 \mathrm{~dB}\right.$, increasing). During the terminal phase, the sperm whale would start with a horizontal click beam and move upwards, increasing its click rate or silencing, before aiming back horizontally so as to start a new search/terminal phase. The low $\mathrm{S} / \mathrm{N}$ ratio during the terminal phases makes difficult the assessment of the acoustical/physical activity of the whale. Nevertheless, the fast click activity and silence would suggest feeding (Miller et al., 2004a).

From the value of the delay $t_{\text {proc }}$, the authors estimate the ranges $r_{\min }$ and $r_{\max }$ during the search phases. At the beginning of the plotted search phases $\left(\mathrm{ICI}_{\max }=1 \mathrm{~s}\right.$ and $\mathrm{ICI}_{\min }$ $=0.5 \mathrm{~s}$ ), the sperm whale would aim at targets located at $r_{\text {min }} \simeq 42 \mathrm{~m}$ and $r_{\text {max }} \simeq 420 \mathrm{~m}$. At the end of the search phase $\left(\mathrm{ICI}_{\max }=0.8 \mathrm{~s}\right.$ and $\left.\mathrm{ICI}_{\min }=0.45 \mathrm{~s}\right)$, it would aim at targets located at $r_{\min } \simeq 30 \mathrm{~m}$ and $r_{\max } \simeq 300 \mathrm{~m}$.

Given the echolocation and the progressive variations of the ICI during a single 5-15-s click burst, decreasing from $\mathrm{ICI}_{\max }$ to $\mathrm{ICI}_{\min }$ before reincreasing to a maximum $\mathrm{ICI}_{\text {max }}^{\prime}$ (Fig. 7), the authors suggest that the whale would echolocate between the ranges $r_{\max }$ and $r_{\min }$ (ICI decreasing from $\mathrm{ICI}_{\max }$ to $\mathrm{ICI}_{\min }$ ) and then back to a maximum range $r_{\max }^{\prime}$ (ICI increasing from $\mathrm{ICI}_{\min }$ to $\mathrm{ICI}_{\max }^{\prime}$ ) every $5-15$-s burst of clicks.

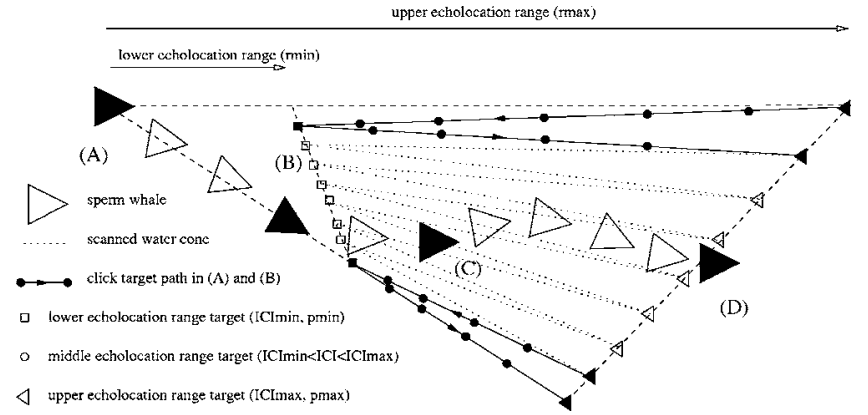

FIG. 9. Sperm whale scan during a search phase. The sperm whale would start scanning the top of a cone of water [from (A), beginning of the search phase], carry on the scan by gradually pointing downwards [to (B)], gradually (but faster) point back upwards [to $(\mathrm{C})]$, before entering the scanned zone and feeding [to (D), end of the terminal phase, beginning of the next search phase]. Click target ranges are plotted here only during the beginning of the first part of a search phase, from (A) to (B).

The authors suggest that during the search phase sperm whales would methodically scan a cone-shaped mass of water searching for prey (Fig. 9). Each scan would last 5-15 s and would analyze the water twice between the upper ranges $r_{\max }$, the lower range $r_{\min }=r_{\max } / \alpha$, and the upper range $r_{\text {max }}^{\prime}$. This scan would suggest that each sperm whale click is generated to aim in a specific direction at a specific range. Sperm whales would move physically to change the click beam direction, and control level and ICI to change the click target range. Similar results have been found during the sperm whale descent studied above.

There are some variations in the geometric features of the scanned water mass: variations within a dive, between dives, and from one sperm whale to another. These geometric features would depend on the number of scans, the ICI minimum and maximum values, the duration of the search phase, and the whale pitch angle variations. For instance, the cones scanned by the whale tracked in 2004 would be shorter (lower ICI) and thinner (only three to four 5-15-s click bursts) than the cone scanned by the whale tracked in 2003, whose ICI sequence is plotted in Fig. 7. This result suggests that sperm whales would, if methodically scanning the prey layer when hunting, adapt their scanning depending on existing prey.

\section{CONCLUSIONS}

The authors have estimated sperm whale pitch angle relative (not absolute) values by studying multipaths at a single hydrophone. Such an estimation enables the authors to analyze sperm whale physical activity during different dive stages: descent and hunt. In both cases, the whale's physical activity correlates to the whale's acoustic activity.

The authors then point out a correlation between click level variations and ICI. The hypothesis explaining such a correlation would be click level control: sperm whales would click slowly at a high source level and faster at a lower source level. Inspired by results found for small odontocete species, the authors propose an echolocation model, click focusing. This echolocation model specifies that sperm whales would aim at closer targets while emitting clicks with lower source level at higher rhythmic rate, and aim at farther 
targets emitting clicks with higher source level and slower rhythmic rate. Based on this hypothesis, the authors compute an echolocation model estimating the sperm whale target range from the ICI.

The authors find a click processing delay of $0.45 \mathrm{~s}$, setting the limit of validity of the sperm whale echolocation model. This value is equal to what has been found by different sources to be the limit between usual clicks and creaks. The authors apply this echolocation model during the descent. The coherency of the model would suggest that sperm whales would indeed, as suggested by different authors, echolocate at the prey layer while vertically descending. Estimated sperm whale pitch angle variations based on this hypothesis are consistent with those found when using tags.

The authors then apply the echolocation model during the hunt at the prey depth. Periodic sperm whale target range variations and pitch movements suggest that sperm whales would scan the water before attacking when foraging. The authors estimate the scanned water mass dimension from the echolocation model.

Finally, the animal range interpolation suggests that sperm whales move at constant heading and speed while hunting. The synthesis of all the results leads the authors to suggest that sperm whales would follow a dive-scale strategy when foraging. Sperm whales would preanalyze their prey layer while descending, and cross this layer by repeating a methodic scanning/catching technique, before resurfacing.

\section{ACKNOWLEDGMENTS}

Thanks to Christophe Guinet of the CEBC-CNRS (Centre d'Etude Biologique de Chizé, France) for initiating this project. Recordings during the 2003 mission could not have been made without the help of Renaud De Stephanis from CIRCé (Conservation Information and Research on Cetaceans, Spain) and Xavier Demoulin from MAREE (Lorient, France). Thanks to the Association Breach (http:// www.breach-asso.org, France) for providing boats, skillful skippers, and ecovolunteers during the 2004 mission, and to the Association Keto $\Sigma$ (France) for undertaking the airborne survey. The MERCATOR Project (France) helped in providing the oceanographic data required for this project. This study was sponsored by the Association Dirac (France). Many thanks to the two anonymous reviewers for their contribution in improving the clarity and the rigorousness of this paper. Also thanks to L. Adam, M. Adam, and M. Campbell for refining the English. Many thanks to F. Rondepierre, L. Mortier (LODYC, Laboratoire d'Océanographie Dynamique et de Climatologie, France), N. Pérez Gimeno (Laboratorio de Acústica y Vibraciones de la Universidad de Cádiz, Spain), V. Toumazou (MERCATOR), and G. Vinay (MERCATOR).

Arnbom, T., and Whitehead, H. (1989). "Observations on the composition and behavior of groups of female sperm whales near the Galapagos Islands," Can. J. Zool. 67, 1-7.

Au, W. (1993). The Sonar of Dolphins (Springer-Verlag, New York).

$\mathrm{Au}$, W., and Herzing, D. (2003). "Echolocation signals of wild Atlantic spotted dolphins (stenella frontalis)," J. Acoust. Soc. Am. 113, 598-604.

$\mathrm{Au}$, W., and Wursig, B. (2004). "Echolocation signals of dusky dolphins (lagenorhynchus obscurus) in Kaikoura, New Zealand," J. Acoust. Soc.
Am. 115, 2307-2313.

Aubauer, R., Lammers, M., and Au., W. (2000). "One-hydrophone method of estimating distance and depth of phonating dolphins in shallow water," J. Acoust. Soc. Am. 107, 2744-2749.

Clay, C. S., and Medwin, H. (1977). Acoustical Oceanography: Principles and Applications (Wiley-Interscience, New York).

Delory, E., Andr, M., and Potter, J. (2002). "An ambient noise imaging sonar to detect nonvocalizing sperm whales," Proceedings of the European Cetacean Society Meeting.

Fristrup, K., and Harbison, G. (2002). "How do sperm whales catch squids?" Marine Mammal Sci. 18(1), 42-54.

Gisiner, R. (1998). Workshop on the effects of anthropogenic noise in the marine environment, pp. 75-96.

Jaquet, N. (1996). "How spatial and temporal scales influence understanding of sperm whale distribution: A review," Mammal Rev. 26, 51-65.

Jaquet, N., Dawson, S., and Douglas, L. (2001). "Vocal behavior of male sperm whales: Why do they click?” J. Acoust. Soc. Am. 109, 2254-2259.

Johnson, M., and Tyack, P. (2003). "A digital recording tag for measuring the response of wild marine mammals to sound," IEEE J. Ocean. Eng. 28(1), 3-12.

Laplanche, C., Adam, O., and Motsch, J. (2004). "Accuracy in the localization of sperm whales resident in the Strait of Gibraltar using one hydrophone," Can. Acoust. 32, 161-166.

Laplanche, C., Adam, O., Lopatka, M., and Motsch, J. (2005). "Real time sperm whale depth estimation using passive acoustics," IEEE Oceans'05 Europe Conf.

Madsen, P., Payne, R., and Kristiansen, N. (2002a). "Sperm whale sound production studied with ultrasound time/depth-recording tags," J. Exp. Biol. 205, 1899-1906.

Madsen, P., Wahlberg, M., and Mohl, B. (2002b). "Male sperm whale (physeter macrocephalus) acoustics in a high-latitude habitat: implications for echolocation and communication," Behav. Ecol. Sociobiol. 53, 31-41.

Madsen, P., Johnson, M., Aguilar de Soto, N., Zimmer, W., and Tyack, P. (2005). "Biosonar performance of foraging beaked whales (mesoplodon densirostris)," J. Exp. Biol. 208, 181-194.

Mccarey, K., and Rubin, J. (1998). "Sea monsters: Search for the giant squid," produced by National Geographic Television.

MERCATOR (2004). "Mercator working for operational oceanography, oceanic analyses and forecasts," http://www.mercator-ocean.fr/en/.

Miller, P., Johnson, M., and Tyack, P. (2004a). "Sperm whale behavior indicates the use of echolocation click buzzes 'creaks' in prey capture," Proc. R. Soc. London, Ser. B 271, (1554), 2239-2247.

Miller, P., Johnson, M., Tyack, P., and Terray, E. (2004b). "Swimming gaits, passive drag and buoyancy of diving sperm whales physeter macrocephalus," J. Exp. Biol. 207, 1953-1967.

Mohl, B., Wahlberg, M., and Madsen, P. (2000). "Sperm whale clicks: Directionality and source level revisited," J. Acoust. Soc. Am. 107, 638648 .

Mohl, B., Wahlberg, M., and Madsen, P. (2003). "The monopulsed nature of sperm whale clicks," J. Acoust. Soc. Am. 114, 1143-1154.

Mullins, J., Whitehead, H., and Weilgart, L. (1988). "Behaviour and vocalizations of two single sperm whales, physeter macrocephalus, off Nova Scotia," Can. J. Fish. Aquat. Sci. 45, 1736-1743.

Rasmussen, M., and Miller, L. (2002). "Source levels of clicks from freeranging white-beaked dolphins (lagenorhynchus albirostris gray 1846) recorded in Icelandic waters," J. Acoust. Soc. Am. 111, 1122-1125.

Santos, M., Clarke, M., and Pierce, G. (2001). "Assessing the importance of cephalopods in the diets of marine mammals and other top predator: Problems and solutions," Fisheries Res. 52, 121-139.

Smith, S., and Whitehead, H. (2000). "The diet of Galapagos sperm whales (physeter macrocephalus) as indicated by fecal sample analysis," Marine Mammal Sci. 16(2), 315-325.

Thode, A., Mellinger, D., and Stienessen, S. (2002). "Depth-dependant acoustic features of diving sperm whales (physeter macrocephalus) in the Gulf of Mexico," J. Acoust. Soc. Am. 112, 308-321.

Wahlberg, M. (2002). "The acoustic behavior of diving sperm whales observed with a hydrophone array," J. Exp. Mar. Biol. Ecol. 281, 53-62.

Wahlberg, M. (2004). "Comparing a linear with a non-linear method for acoustic localization," Can. Acoust. 32, 125-131.

Watkins, W., and Schevill, W. (1977). "Sperm whale codas," J. Acoust. Soc. Am. 62, 1485-1490.

Watkins, W., Daher, M., and DiMarzio, N. (1999). "Sperm whale surface activity from tracking by radio and satellite tags," Marine Mammal Sci. 15(4), 1158-1180. 
Watkins, W., Daher, M., and Fristrup, K. (1993). "Sperm whales tagged with transponders and tracked underwater by sonar," Marine Mammal Sci. 9(1), 55-67.

Weilgart, L. (1990). "Vocalizations of the sperm whale, physeter macrocephalus, off the Galapagos Islands as related to behavioral and circumstantial variables," Ph.d. thesis, Dalhousie University, Halifax.

Whitehead, H., and Weilgart, L. (1990). "Click rates from sperm whales," J. Acoust. Soc. Am. 87, 1798-1806.
Zimmer, W., Johnson, M., D'Amico, A., and Tyack, P. (2003). "Combining data from a multisensor tag and passive sonar to determine the diving behavior of a sperm whale (physeter macrocephalus)," IEEE J. Ocean. Eng. 28(1), 13-28.

Zimmer, W., Tyack, P., Johnson, M., and Madsen, P. (2005). "Threedimensional beam pattern of regular sperm whale clicks confirms benthorn hypothesis," J. Acoust. Soc. Am. 117, 1473-1485. 